\title{
AJUSTE DO MODELO MATEMÁTICO DOS FORNOS DE REAQUECIMENTO DE PLACAS PARA OPERAÇÃO COM GÁS NATURAL*
}

Antonio Adel dos Santos ${ }^{1}$
Marcos Henrique Teixeira
Vinícius Amaral Marques

\section{Resumo}

Em agosto/2014 foi introduzido o gás natural, GN, na matriz de combustíveis dos fornos de reaquecimento de placas da Linha de Tiras a Quente, em Ipatinga, eliminando o óleo combustível deste processo. Isto demandou o ajuste dos parâmetros do modelo matemático de controle automático do reaquecimento, que estava ajustado para a queima de mistura de gases siderúrgicos e óleo combustível. $O$ ajuste foi realizado com base em resultados de experiências de medição das curvas de aquecimento com placas especialmente instrumentadas. Verificou-se que os gases da combustão na presença do GN ficam mais quentes na região do início do forno, próximo do canal de fumaça, elevando com isso o perfil térmico do forno. Em consequência, as temperaturas de desenfornamento da placa ficam mais elevadas em relação ao aquecimento na ausência do GN, comparando-se condições de processo e de material similares. Os ajustes do modelo foram implantados dentro do escopo de uma melhoria geral introduzida no sistema de controle automático dos Fornos, permitindo a determinação correta da temperatura de desenfornamento e a operação otimizada dos fornos do ponto de vista de aquecimento da placa.

Palavras-chave: Forno de reaquecimento; Modelo matemático; Temperatura de placa; Gás natural.

\section{FITTING THE MATHEMATICAL MODEL FOR REHEATING FURNACES FOR SLABS OPERATING WITH NATURAL GAS}

\section{Abstract}

The reheating furnaces for slabs of Usiminas Hot Strip Mill in Ipatinga started operating with natural gas, NG, in August 2014. This required the fitting of model related parameters that were used for operation with in-house generated gases and fuel oil. This fitting was based on results from experiments carried out with instrumented slab for temperature measurement. It was found that the combustion gases become hotter in the rear of furnace, close to their exit to stack, when NG was used. Thus, higher slab discharging temperature was achieved regarding the operation with this new fuel condition. The fitted parameters were introduced in the operating control system, which was revamped, allowing more precise calculation of discharging temperature and optimized operation condition regarding slab heating.

Keywords: Reheating furnace; Mathematical model; Slab temperature; Natural gas.

1 Engenheiro Metalurgista, DSc., CQE/ASQ, Pesquisador Especialista Sênior, Centro de Tecnologia Usiminas, Ipatinga, MG, Brasil.

2 Engenheiro Eletricista, MSc., Especialista, Engenharia de Desenvolvimento de Projetos, Usiminas, Ipatinga, MG, Brasil.

3 Engenheiro de Materiais, Assistente Técnico Industrial, Laminação de Tiras a Quente, Usiminas, Ipatinga, MG, Brasil. 


\section{INTRODUÇÃO}

Os fornos de reaquecimento de placas da Linha de Tiras a Quente (LTQ) da Usiminas, Ipatinga, operam com determinação automática de set point de temperatura das zonas desde 1999. O modelo matemático existente no sistema de automação foi desenvolvido pela empresa japonesa SMICEC. Na época de seu comissionamento foi realizado um ajuste inicial dos parâmetros para as condições de processo vigentes. A base para o ajuste são os resultados das curvas de aquecimento medidas em posições específicas no interior da placa. Em função de alterações nas condições operacionais, tempo de vida dos fornos e mudanças na matriz de combustíveis usados, novos ajustes desses parâmetros foram realizados ao longo do tempo. O objetivo principal do ajuste é propiciar que o modelo faça uma precisa estimativa da temperatura de desenfornamento da placa, além de adequar as temperaturas de zonas visando minimização de consumo de combustíveis e formação de carepa.

No segundo semestre de 2014 esses fornos passaram a operar com GN em sua matriz de combustíveis, além dos gases siderúrgicos já usados, eliminando a queima de óleo. Com isso, foi necessário fazer uma atualização e melhoria do sistema de controle automático das zonas. Dentro do escopo deste projeto foi realizado o ajuste do modelo matemático de cálculo da evolução da temperatura da placa durante o aquecimento. O ajuste foi baseado nos resultados de duas experiências de medição de temperatura da placa, uma para cada forno, numerados 4 e 5 , da LTQ.

\section{PRINCIPAIS PARÂMETROS DE AJUSTE DO MODELO}

O modelo matemático utiliza uma malha bidimensional na espessura e em parte do comprimento da placa, com 45 nós (pontos de cálculo da temperatura), como ilustrado na figura 1. A transferência de calor no interior da placa ocorre por condução térmica, regido pela equação de difusão de Fourier [1-3].

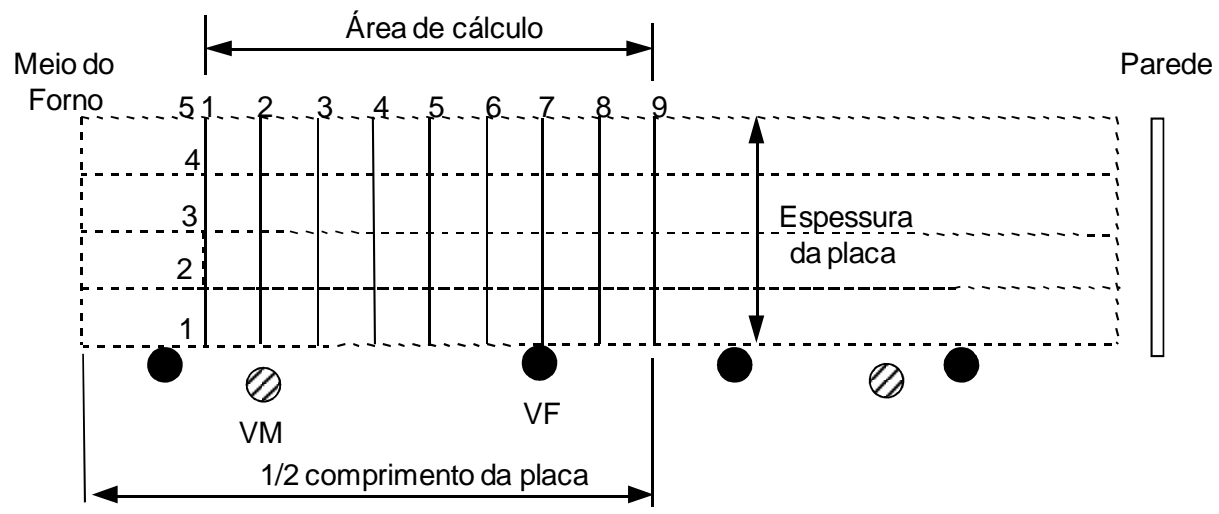

Figura 1. Malha de cálculo de temperatura do modelo matemático dos Fornos de Reaquecimento da LTQ, Usiminas, Ipatinga. VM: viga móvel, VF: viga fixa. Neste esquema, a placa é curta, $6 \mathrm{~m}$, ocupando uma ala do Forno.

Do ambiente do forno para a superfície da placa a transferência de calor ocorre por radiação e convecção térmica. Uma vez que o primeiro mecanismo é predominante, o cálculo do fluxo de calor total do ambiente para a placa é dado pela equação (1). Esta expressão é uma forma da lei de Stefan-Boltzmann de emissão de calor por radiação, adaptada para o modelo do forno de reaquecimento. O parâmetro $\phi_{c G}$ 
representa uma emissividade aparente do ambiente do forno para a superfície da placa, sendo um dos parâmetros de ajuste do modelo. São considerados doze valores de $\phi_{C G}$, seis para o ambiente superior e seis para o inferior do forno (dois por zona).

$$
q=\phi_{C G} \sigma\left[F\left(T_{a}\right)^{4}+(1-F)\left(T_{v}\right)^{4}-\left(T_{s}\right)^{4}\right]
$$

Onde:

q: fluxo de calor do forno para a placa $\left(W . \mathrm{m}^{-2}\right)$;

$\phi_{C G}$ : emissividade aparente do ambiente do forno para a placa (-);

F: fator de vista (-);

$\sigma:$ constante universal de Stefan-Boltzmann $\left(5,67 \cdot 10^{-8} \mathrm{~W} \cdot \mathrm{m}^{-2} \cdot \mathrm{K}^{-4}\right)$;

$\mathrm{T}_{\mathrm{s}}$ : temperatura da superfície da placa $(\mathrm{K})$;

$\mathrm{T}_{\mathrm{a}}$ : temperatura ambiente do forno $(\mathrm{K})$;

$\mathrm{T}_{\mathrm{v}}$ : temperatura das vigas $(\mathrm{K})$.

Outros dois conjuntos de parâmetros de ajuste do modelo também estão relacionados à equação (1). O segundo se refere ao cálculo da temperatura ambiente do forno. A temperatura das zonas é controlada pelas indicações e set points estabelecidos para os termopares instalados em cada zona. No caso dos fornos da LTQ são dois termopares para cada uma das seis zonas dos fornos. Porém, a temperatura ambiente próxima da placa (perfil térmico), aplicada na equação (1), difere daquela indicada pelos termopares e varia ao longo do comprimento do forno. Portanto, $\mathrm{T}_{\mathrm{a}}$ é parametrizada em função da posição ao longo do forno e das temperaturas das zonas de pré-aquecimento, aquecimento e encharque, respectivamente $T_{\text {Pre, }} T_{\text {Aqu }}$ e $T_{\text {Enc }}$, conforme esquema da figura 2 , totalizando quinze parâmetros.

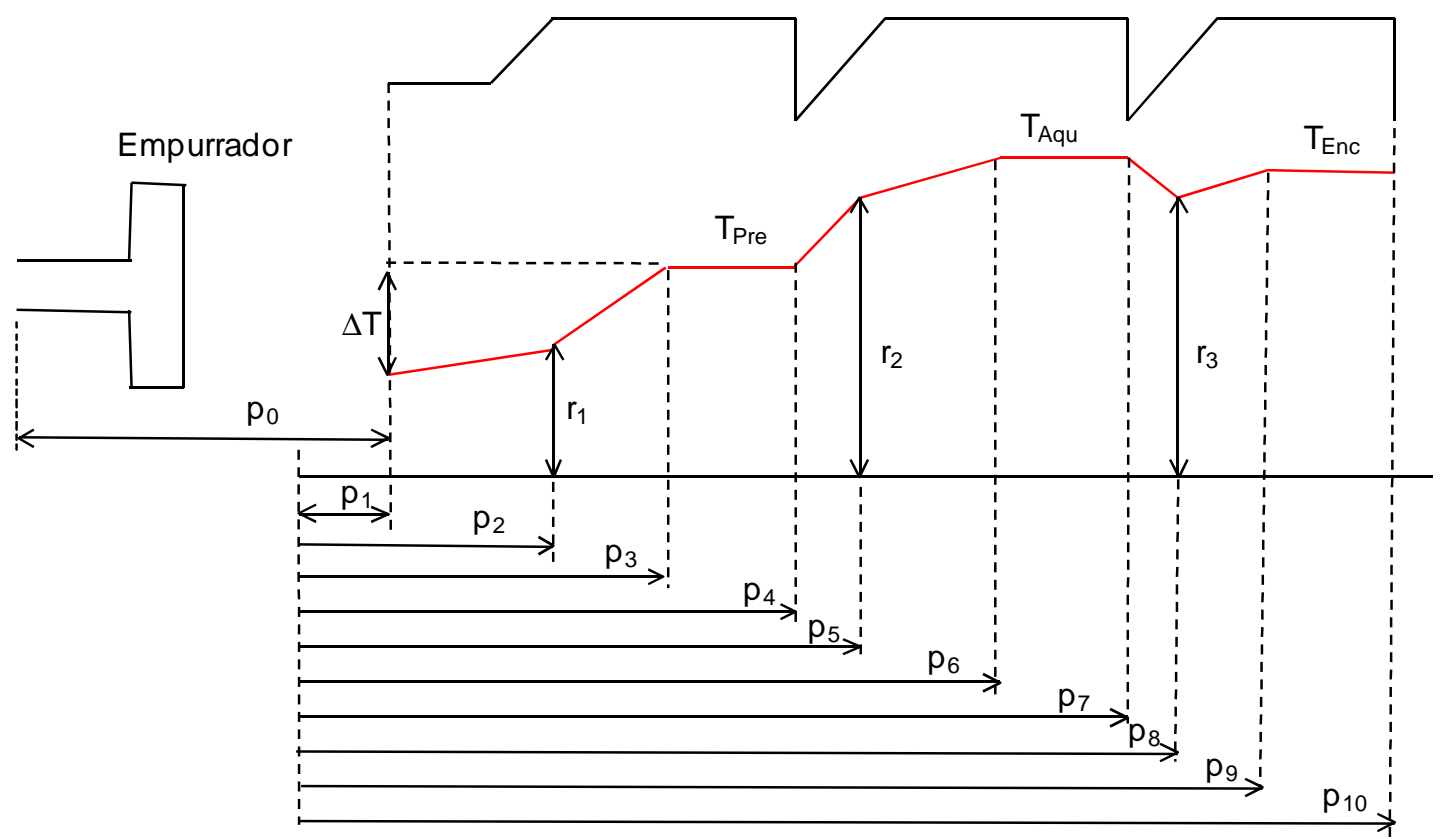

Figura 2. Parâmetros de ajuste de cálculo do perfil térmico do forno: $p_{0} . . p_{10} ; r_{1}, r_{2}, r_{3}, \Delta T$. $T_{\text {Pre }}, T_{\text {Aqu }} e$ $\mathrm{T}_{\text {Enc }}$ são as temperaturas de set point das zonas.

O terceiro conjunto de parâmetros se refere ao cálculo da temperatura da viga fixa, também usada na equação (1), descrita por uma função linear da temperatura superficial da placa. Os dois coeficientes desta equação são os parâmetros de ajuste para cada zona. Totalizando, são trinta e três valores de parâmetros de ajuste 
do modelo: doze valores de $\phi_{\mathrm{CG}}$, quinze do perfil térmico e seis para a temperatura de viga.

\section{METODOLOGIA}

Experiências de medição das curvas de aquecimento de placas foram realizadas nos fornos 4 e 5 , ambos operando com uma mistura de gases siderúrgicos mais GN. Este tipo de experiência, com a placa instrumentada, tem sido realizado com frequência no processo industrial das linhas de tiras a quente e de chapas grossas da Usiminas, com o dispositivo desenvolvido no Centro de Tecnologia Usiminas. Termopares foram inseridos em locais selecionados em uma placa especialmente preparada e foram conectados a um coletor de dados, isolado termicamente por uma caixa de proteção inserida na placa. A placa foi aquecida em condição normal de processo. Os termopares usados foram do tipo $\mathrm{K}$, com $6,0 \mathrm{~mm}$ de bainha e revestimento de $\mathrm{MgO}$ de alta pureza. As curvas medidas, juntamente com as condições operacionais do forno durante a experiência, foram usadas na análise de dados e ajuste dos parâmetros do modelo. Na figura 3 é mostrada uma fotografia da placa preparada para enfornamento em uma das experiências.

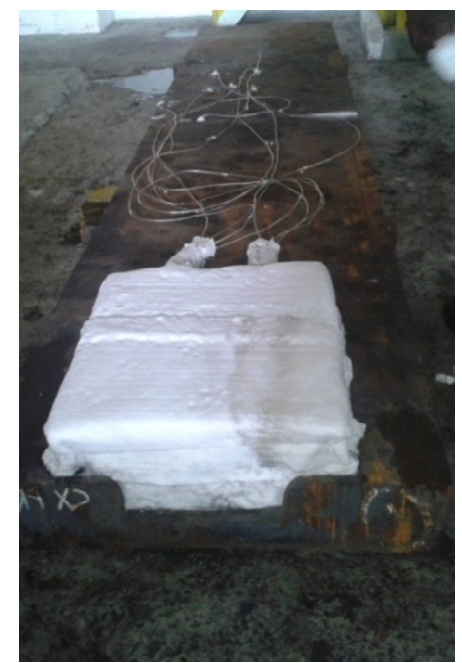

Figura 3. Fotografia da placa instrumentada para enfornamento em uma das experiências realizadas.

\section{RESULTADOS E DISCUSSÃO}

Devido à similaridade da análise para os dois fornos, serão mostrados resultados relativos apenas à experiência realizada no Forno 4. São mostrados e discutidos os resultados da experiência, as curvas de aquecimento previstas para a operação na ausência do GN, situação anterior, e aquelas após o ajuste introduzido para considerar a operação com o GN na mistura gasosa combustível.

\subsection{Resultados Experimentais}

Para o ajuste do modelo, é visada a estabilidade operacional do forno durante a experiência, em termos de manutenção da mistura de combustível e dos set points de temperatura de zona, além de ritmo constante de desenfornamento.

$\mathrm{Na}$ figura 4 são mostradas as temperaturas de zonas, medidas pelos termopares de controle, na parte superior do forno, no período de realização da experiência. Propositalmente, o set point das zonas é fixado e mantido pelo sistema supervisório, 
nos valores previamente estabelecidos. As linhas verticais na figura denotam o momento que a placa mudou de zona e a temperatura média indicada corresponde ao período de passagem da placa pela zona. Nota-se a estabilidade operacional obtida.

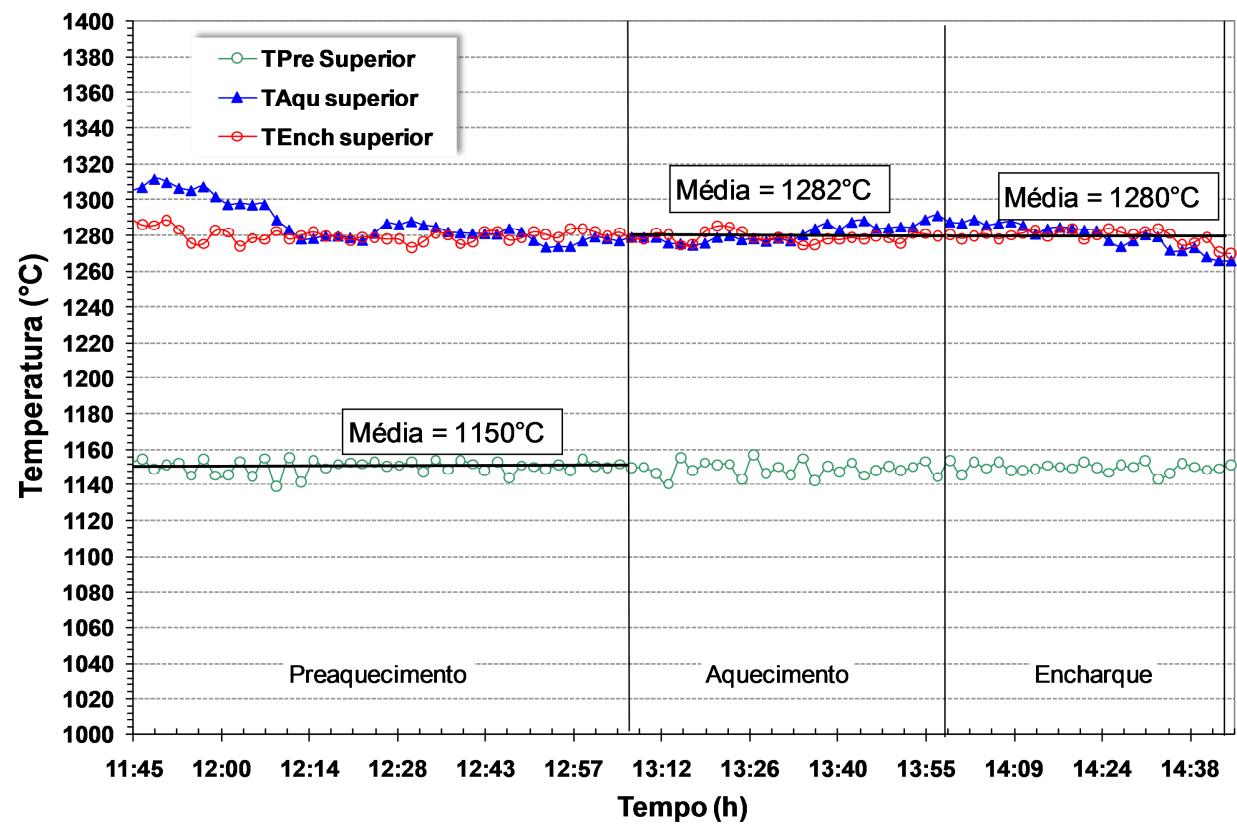

Figura 4. Temperaturas dos termopares de controle das zonas superiores do forno no período da experiência.

O ritmo de deslocamento da placa no forno foi obtido pela sua posição, obtida no traqueamento da placa, em função do tempo ou posição da experiência. Na figura 5 é mostrado o gráfico obtido. A linearidade dos pontos indica o ritmo constante de desenfornamento.

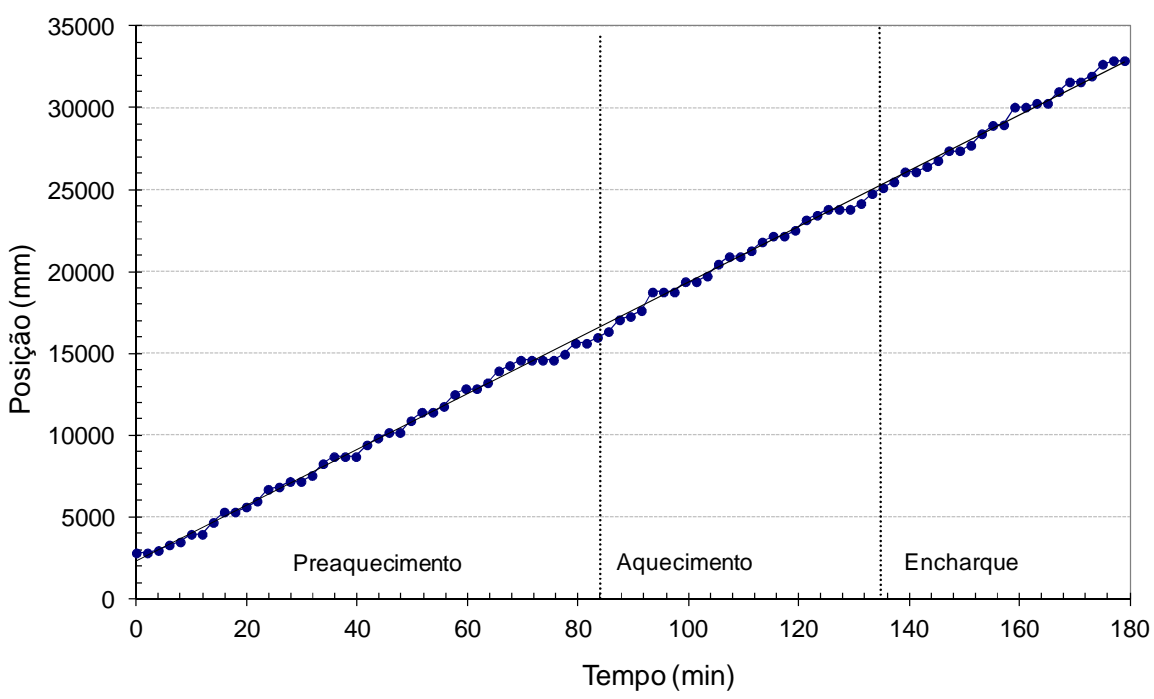

Figura 5. Posição da placa instrumentada em função do tempo durante sua passagem pelo forno. 


\subsection{Curvas de Aquecimento}

Na figura 6 está mostrada a posição dos termopares inseridos na placa em relação à malha de cálculo do modelo. Para a experiência no Forno 4 foram seis termopares inseridos na placa, T1 a T6, e dois que mediram a temperatura ambiente próximo à placa, T7 e T8 (antenas). A área hachurada indica a região de influência do nó (ponto da malha). A diferença de seu tamanho se deve à não uniformidade dos espaçamentos e à diferente posição de cada nó, superfície ou centro.

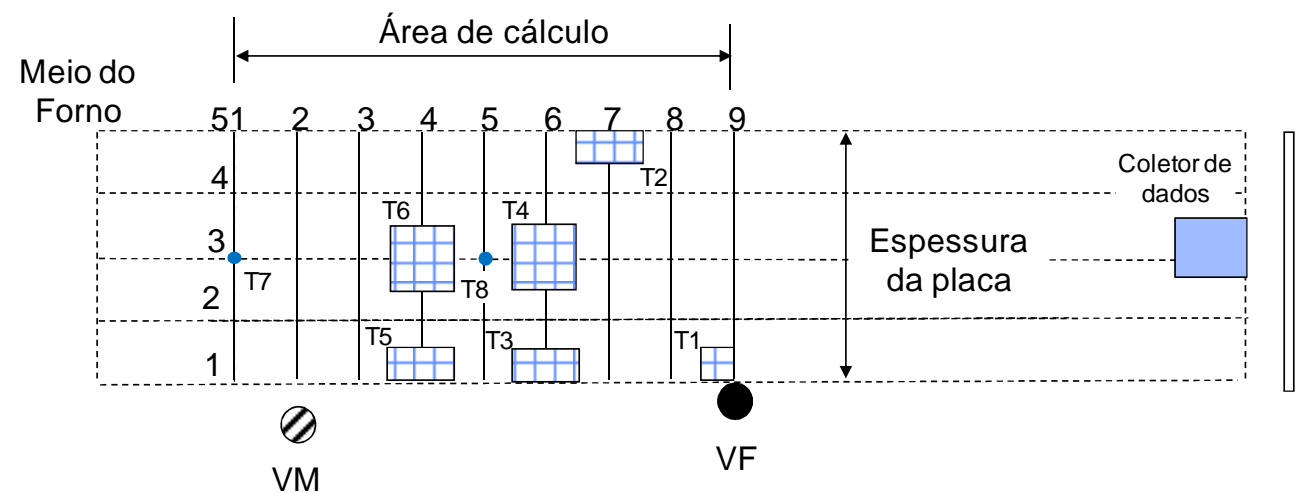

Figura 6. Posição dos pontos de medição de temperatura em relação à malha de cálculo do modelo para o Forno 4.

Foram comparados os valores medidos com os calculados pelo modelo em tempo real, durante a experiência. Além da comparação para cada termopar, foram desenvolvidas metodologias no trabalho que permitem, a partir das curvas individuais medidas, estimar as curvas de aquecimento da superfície superior da placa, da superfície inferior, do meio da espessura e a média global da placa. A questão chave é que, para o modelo, 45 valores de temperatura são disponíveis, dos quais a média global é feita pela ponderação pelas áreas de influência. Para estimar a temperatura média medida, são apenas seis valores disponíveis.

As curvas de temperatura média no aquecimento são mostradas na figura 7. A curva "Modelo online" foi obtida pela cálculo em tempo real pelo modelo. A curva "Tmédia_geral calc." é a calculada empregando-se os seis valores fornecidos nas posições T1 a T6 pelo modelo em tempo real e aplicando-se a metodologia desenvolvida. A curva "Tmédia_geral med." é a medida empregando-se a mesma metodologia aos seis valores medidos. Observa-se que a curva média estimada a partir dos 6 valores gerados pelo cálculo online do modelo fica muito próxima da curva calculada geral considerando-se os 45 nós da malha. Isto atesta a validade do esquema usado de cálculo da temperatura média da placa a partir dos 6 valores correspondentes às posições dos termopares. A temperatura medida, no entanto, ficou acima da calculada. Uma vez que o modelo estava ajustado para a queima de gases siderúrgicos, esta diferença foi atribuída à utilização do GN na mistura.

O gráfico com o perfil térmico do forno previsto para a operação sem GN é mostrado na figura 8, juntamente com o perfil térmico medido pelos termopares T7 e T8 na operação com o GN. A comparação dos perfis indica que o ambiente (os gases de combustão), na queima com o GN, estão mais quente que o esperado para a queima sem GN, na zona de pré-aquecimento. Esta é uma das razões para a temperatura mais alta medida na placa que a calculada, como mostrado na figura 7 . 


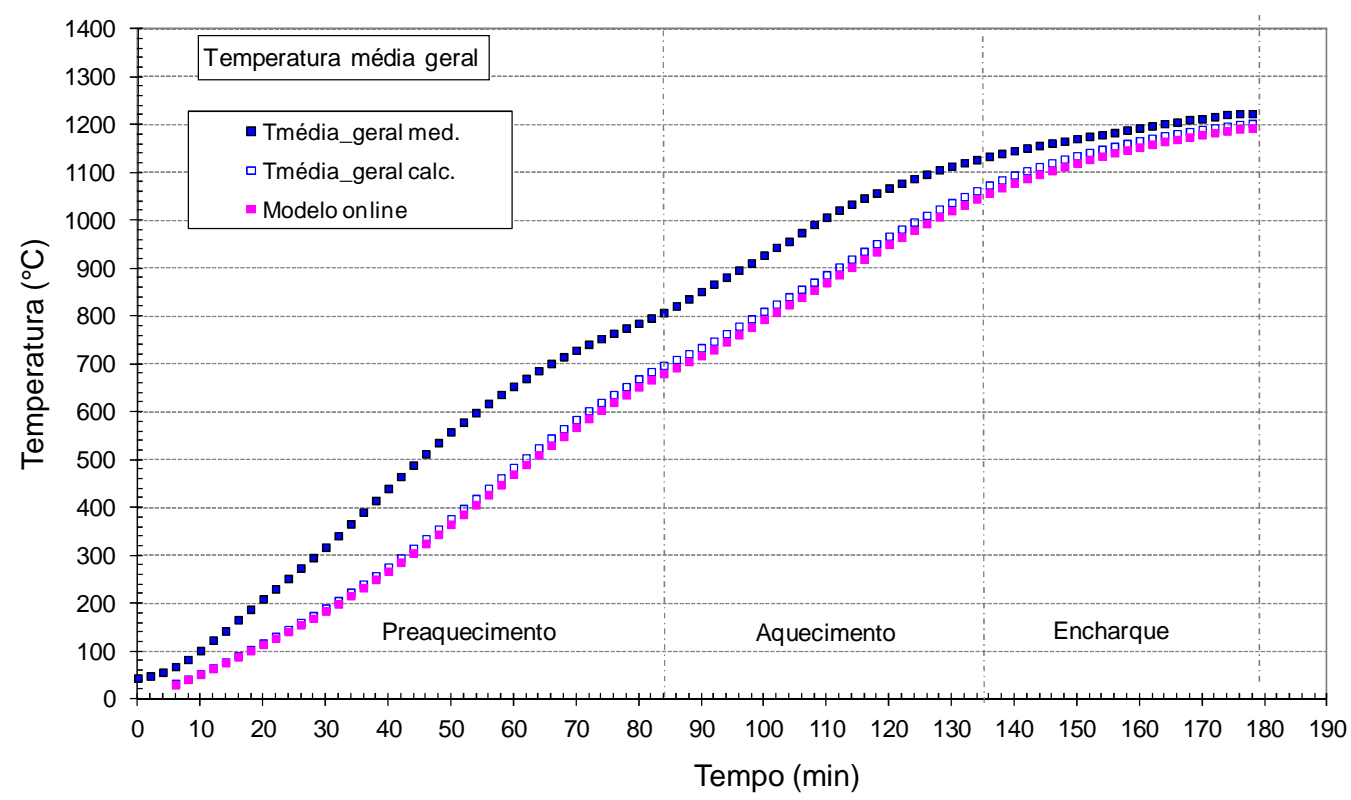

Figura 7. Curvas de temperatura média medida e calculada da placa no aquecimento.

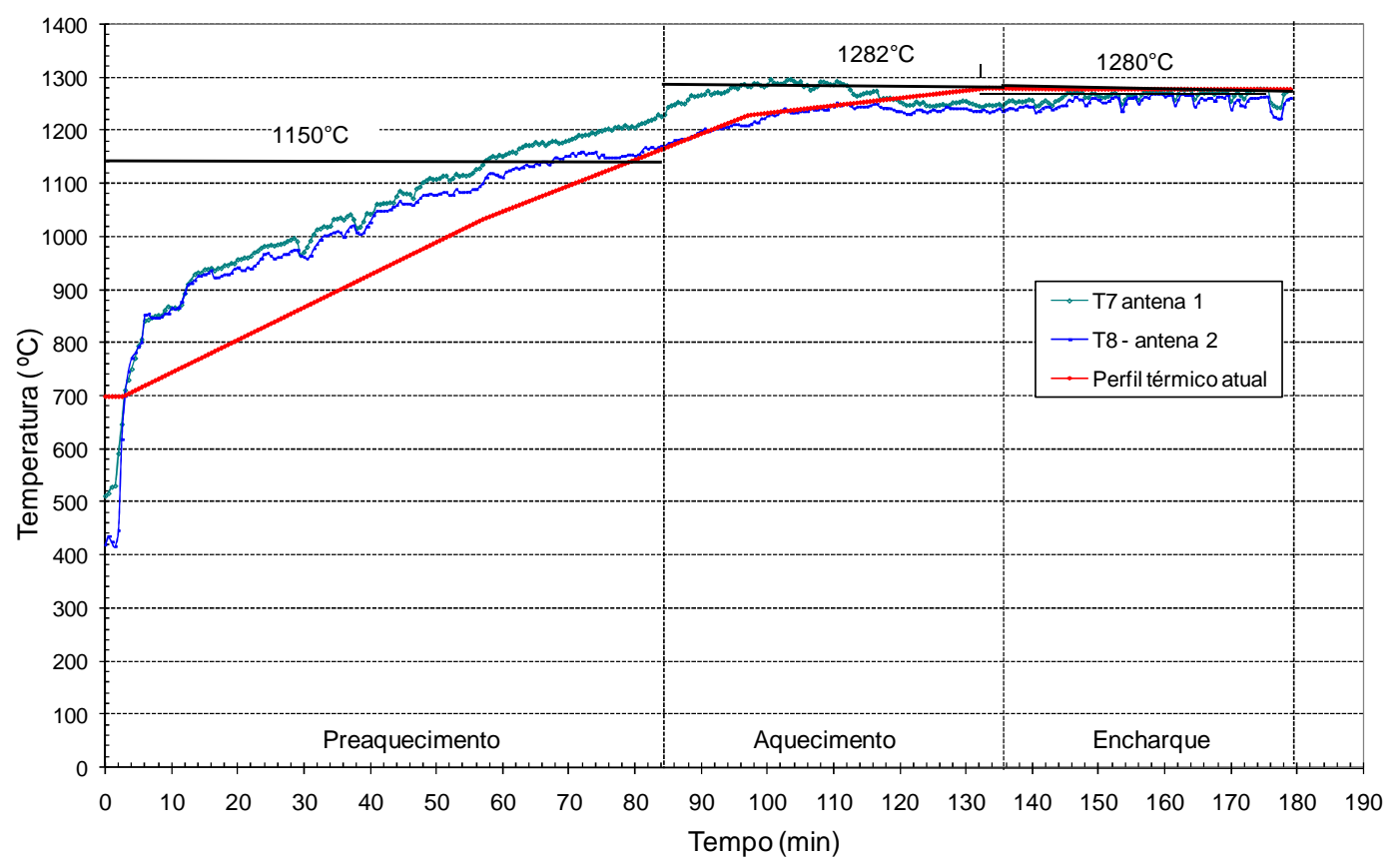

Figura 8. Perfil térmico calculado para o ajuste do modelo na condição operacional sem GN, e perfil medido (termopares antena, T7 e T8) na experiência com o uso de GN.

\subsection{Ajuste dos Parâmetros do Modelo}

O primeiro passo foi o ajuste dos parâmetros do perfil térmico do forno, figura 2. Como somente na zona de pré-aquecimento o perfil estava subestimado, foram alterados os valores $\Delta T, p_{2}, p_{3}$ e $r_{1}$. Com isso, o novo perfil adequado para a operação com GN na mistura, calculado pelo modelo, é mostrado na figura 9, juntamente com o perfil medido. A aproximação entre ambos é satisfatória. 


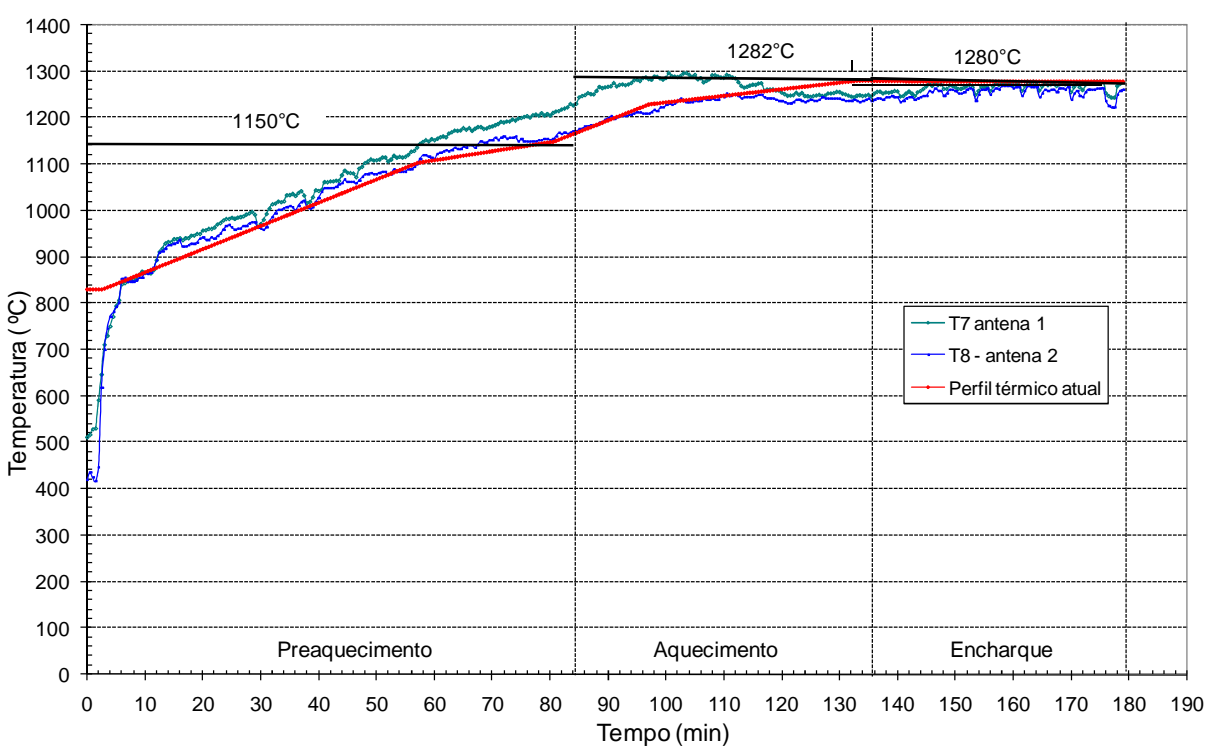

Figura 9. Perfil térmico calculado após ajuste dos parâmetros para o $\mathrm{GN}$, e perfil medido na experiência.

Posteriormente, foram ajustados os parâmetros de $\phi_{\mathrm{CG}}$ e de temperatura da viga fixa, primeiro e terceiro conjuntos citados anteriormente. As alterações foram no sentido de elevar tais parâmetros visando a aproximação das curvas calculadas daquelas medidas. Para verificar tal aproximação, foram feitas simulações matemáticas offline, com o simulador do reaquecimento de placas do modelo (uma versão offline do modelo de controle), após correção dos parâmetros do perfil térmico. Na tabela 1 são mostrados os valores de $\phi_{\mathrm{CG}}$, por zona, para a operação do forno com gases siderúrgicos e para a situação atual, com GN na mistura de combustíveis.

Tabela 1. Valores de $\phi_{C G}$ anteriores e ajustados para a operação com GN.

\begin{tabular}{lccc}
\hline Zona & Pré-aquecimento & Aquecimento & Encharque \\
\hline Valor anterior & 0,85 & 0,81 & 0,78 \\
Ajustado para GN & 0,90 & 0,85 & 0,80
\end{tabular}

As curvas de aquecimento simuladas com o modelo ajustado, e que serão calculadas pelo modelo online, na condição de aquecimento da placa instrumentada são mostradas nas figuras de 10 a 12, para a superfície superior, superfície inferior e média global da placa, nesta ordem. Nessas figuras estão três curvas: a medida, a calculada online (em tempo real) durante o aquecimento da placa instrumentada e a simulada offline com os parâmetros ajustados, chamada "SimulaçãoFCG". A aproximação entre as curvas previstas e medidas demonstra o bom ajuste do modelo. Somente a temperatura média simulada ficou ligeiramente abaixo da medida, o que representa uma condição conservadora operacional para evitar desenfornamento em temperatura baixa, o que causaria problemas nos processos seguintes.

Os valores ajustados foram implantados no sistema automático de controle dos fornos, de forma gradual, dentro de um programa de gestão de mudanças, com acompanhamento de eventuais impactos negativos da produção, o que não aconteceu. 


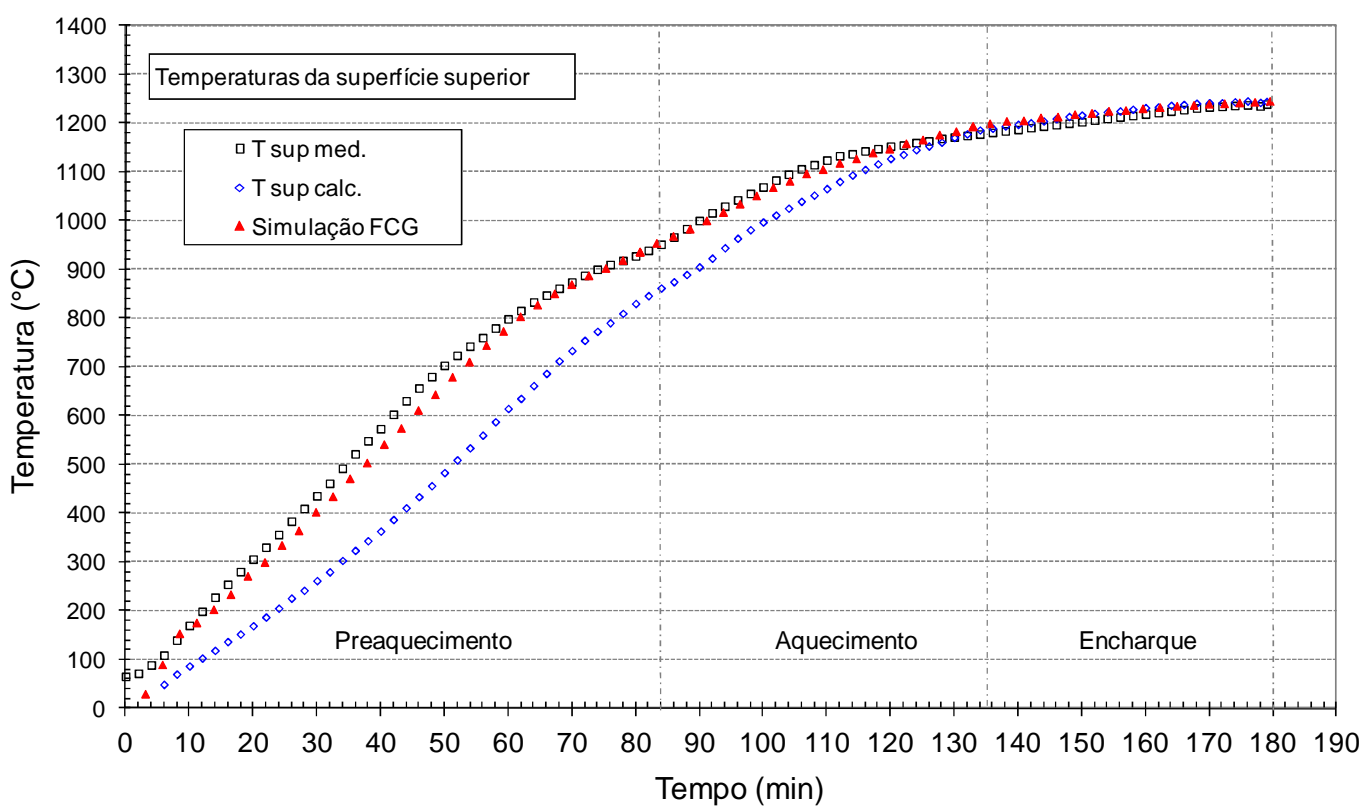

Figura 10. Curva de aquecimento medida e curvas calculadas na superfície superior da placa, antes, "Tsup calc", e depois, "SimulaçãoFCG", do ajuste dos parâmetros para operação com GN na mistura.

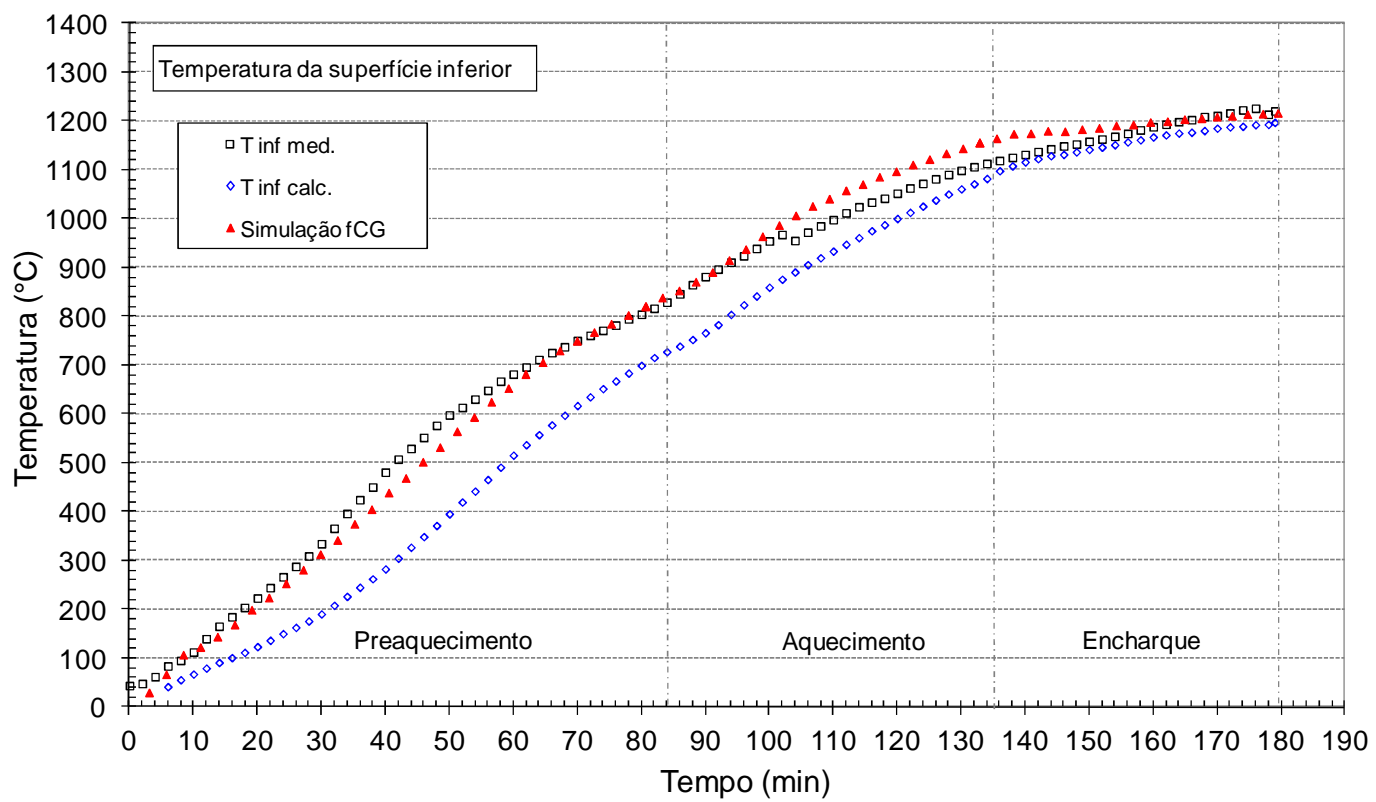

Figura 11. Curva de aquecimento medida e curvas calculadas na superfície inferior da placa, antes, "Tinf calc", e depois, "SimulaçãoFCG", do ajuste dos parâmetros para operação com GN na mistura. 


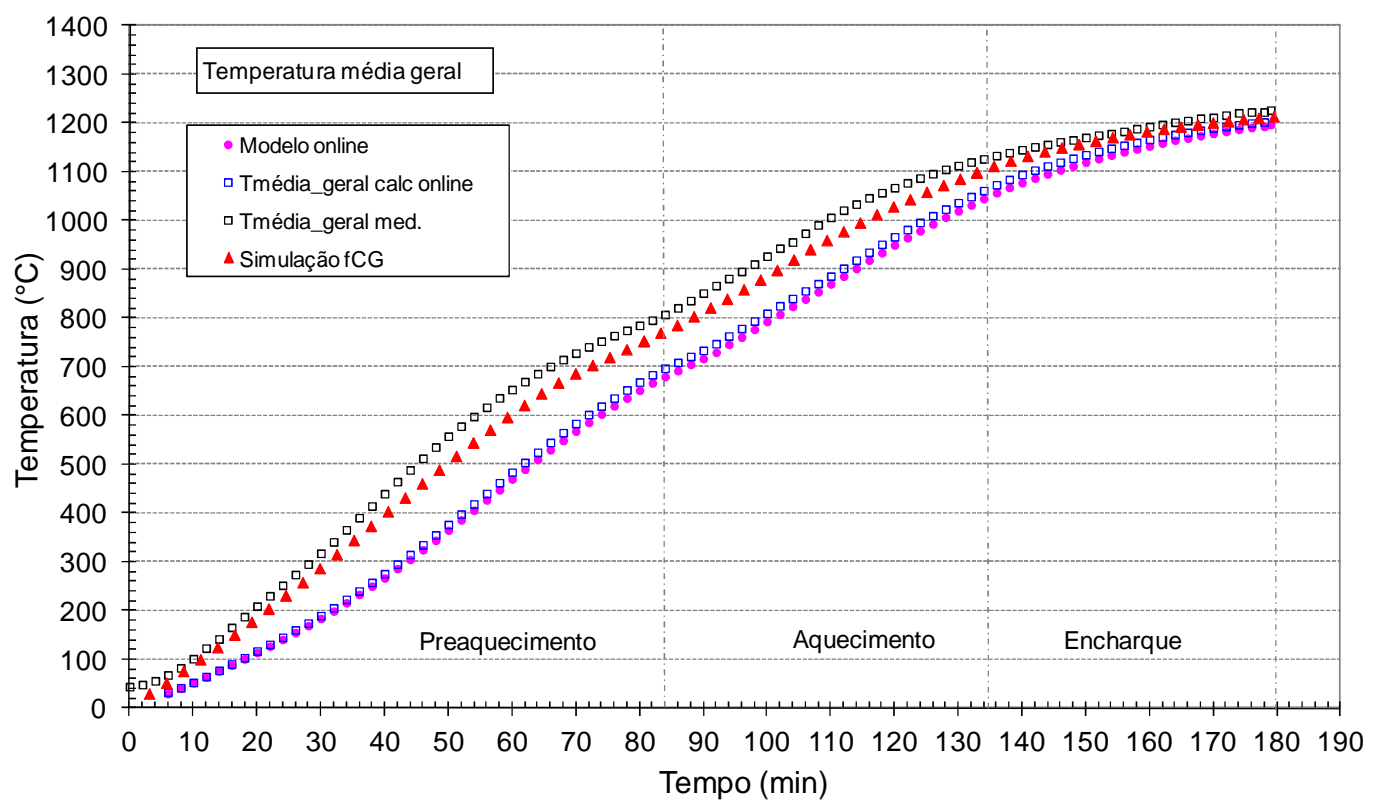

Figura 12. Curva de aquecimento medida e curvas calculadas da média global da placa, antes, "Modelo online", e depois, "SimulaçãoFCG", do ajuste dos parâmetros para operação com GN na mistura.

\section{CONCLUSÃO}

A introdução do GN na mistura de combustíveis para operação dos fornos de reaquecimento de placas da Linha de Tiras a Quente da Usiminas causou elevação da temperatura do ambiente do forno, especialmente na zona de pré-aquecimento. Isso foi percebido também pela elevação da temperatura da fumaça na entrada da chaminé. As experiências de medição de curvas de aquecimento da placa, com a placa instrumentada, permitiram avaliar esta elevação de temperatura do forno, com consequente aumento da temperatura de desenfornamento de placa. Com base nos resultados medidos foram determinados ajustes dos parâmetros do modelo matemático de controle de aquecimento da placa, para operação com GN, garantindo a correta previsão da temperatura de desenfornamento e adequação no cálculo de set point de temperaturas de zonas.

\section{Agradecimentos}

Aos diversos colaboradores da Usiminas que participaram do trabalho de ajuste do modelo, em especial: Arthur de Castro Souza, Júlio Henrique de Araújo Rosa, Priscila Batista Dias, Richardson Ramos Pacó.

\section{REFERÊNCIAS}

1 Panjkivic V, Gloss R. Fast dynamic heat and mass balance model of walking beam reheat furnace with two-dimensional slab temperature profile, Ironmaking and Steelmaking, 2012,39( 9): 190-209.

2 Staalman $\mathrm{D}$. The funnel model for accurate slab temperature in reheating furnaces, La Révue de Metallurgie, 2004,101(6): 453,-459.

3 Santos AA, Schiavo CP, Giacomin CN. Simulação computacional do processo de reaquecimento de placas em fornos de viga móvel, Tecnologia em Metalurgia e Materiais, 2008, 5(1): 35-39. 